\title{
Elementos para una teoría general de la igualdad y la no-discriminación a partir de la experiencia del derecho europeo
}

\section{Elements for a general theory of equality and non discrimi- nation regarding European experience}

\section{DANIEL BORRILLO*}

Resumen: El artículo analiza las consecuencias del tránsito del Estado moderno al Estado de bienestar en la definición del principio de igualdad, para posteriormente explicarnos las implicancias de la promoción del principio de no-discriminación y su configuración como factor de caución de la libre competencia. A partir de ello nos aproxima a los principales instrumentos del derecho europeo de la no-discriminación, para seguidamente explicarnos detalladamente los tres componentes de la discriminación: tracto, criterium y spatium. Finalmente, aborda la problemática de la prueba en materia de discriminación y la obligación de promover la igualdad que tienen los Estados en el derecho europeo.

Palabras clave: igualdad - discriminación - tracto - criterium - spatium

Summary: The article analyzes the implications of shifting from modern to a welfare state according with the definition of equality principle, then explains the consequences of promoting the non discrimination principle and its structure as surety element of free competition. On that basis, the author presents the main tools of non discrimination in European law and then gives details about three components of discrimination: "tracto, criterium and spatium". Finally, the article explores the debate surrounding the notion of evidence when it is related to discrimination, emphasizing States duty on promoting equality in European law.

Key words: equality - discrimination - tracto - criterium - spatium

CONTENIDO: I. INTRODUCCIÓN: EL PRINCIPIO DE IGUALDAD Y NO DISCRIMINACIÓN.- II. LA ESTRUCTURA DE LA NO-DISCRIMINACIÓN.III. LA PRUEBA EN MATERIA DE DISCRIMINACIÓN.- IV. LA NO-DISCRIMINACIÓN Y LA PROMOCIÓN DE LA IGUALDAD.

Profesor de Derecho Privado en la Universidad de Paris Ouest Nanterre. Investigador asociado al Centro Nacional para la Investigación Científica de Francia (CNRS). Correo electrónico: borrillo@u-paris10.fr 


\section{INTRODUCCIÓN: EL PRINCIPIO DE IGUALDAD Y NO-DISCRIMINACIÓN}

La afirmación del principio de igualdad es uno de los fundamentos constitutivos de la democracia. El Estado moderno se construyó contra los regímenes de privilegio, y al proclamar la unidad del género humano, sentó las bases del ideal igualitario. Desde el siglo XIX, el conjunto de las constituciones nacionales de Europa consagra el principio de igualdad, inspirándose de la Revolución francesa. La Declaración de Derechos del Hombre y del Ciudadano de 1789 establece en su artículo primero que «los Hombres nacen y permanecen libres e iguales en derechos» y más tarde recuerda que «los Hombres son por naturaleza iguales ante la ley».

Dicho principio (formal) se mostró rápidamente insuficiente y fue necesario elaborar instrumentos más eficaces de realización de aquel ideal a partir de lo que, en el siglo XX, se dio en llamar igualdad sustantiva, material o de hecho. El Estado de bienestar aparece en Europa como la instancia más avanzada en la concretización del principio de igualdad material. Sin embargo, un malentendido estructural socavará la ejecución efectiva de dicho principio. En efecto, el Estado de bienestar confundió igualdad material con redistribución económica, al pensar que la resolución de la pobreza traería aparejada la igualdad y olvidando contemplar situaciones de discriminación en las que no existía exclusión económica. Por ejemplo, un hombre gay blanco de la alta burguesía, que aunque se encuentre en el grupo económico dominante se puede sentir, sin embargo, discriminado, ya que no tiene acceso al derecho al matrimonio.

La creencia de que la igualdad económica produciría la igualdad real encontró rápidamente sus límites. En ese sentido, el principio de no-discriminación es más modesto y por ello quizás también más conservador, ya que renuncia al ideal de una sociedad igualitaria en sentido global para concentrarse, de un modo pragmático, en la creación de un espacio de igualdad de oportunidades. El Estado no garantiza resultados equiparables, sino simplemente el acceso potencial a ciertos bienes sociales, económicos o culturales a todas las personas en situaciones análogas.

En la Unión Europea, la lucha contra todas las formas de discriminación se ha convertido en el primer programa político que va más allá de la pura integración económica. Dicho programa es el resultado del compromiso entre tres grandes tradiciones europeas: el sistema liberal anglosajón, el sistema de intervención estatal directa de tipo continental (Francia y Alemania) y el sistema escandinavo de diálogo social permanente pero sin intervención necesaria del Estado 1 .

1 BoRRILLO, Daniel (dir.). Lutter contre les discriminations. París: La Découverte, coll. «Recherches», 2003. 
Rápidamente la promoción del principio de no-discriminación ha aparecido como un factor de caución de la libre competencia, ya que, por un lado, la ausencia de discriminación propicia una concurrencia no alterada por la intromisión de elementos irracionales de los actores económicos víctimas de prejuicios, y por el otro, la no-discriminación favorece la potencialización de las capacidades de los agentes del mercado, independientemente de sus condiciones particulares. El tratado de Ámsterdam de 1997 (que entró en vigor en 1999) intenta así conciliar desarrollo económico y pleno empleo, privilegiando la participación en el mercado del trabajo a través de la integración social. No es casual que dicho tratado introduzca en el derecho de la Unión Europea la lucha contra la discriminación como una de las políticas prioritarias del continente.

Como consecuencia de dicho tratado se han implementado dos directivas comunitarias fundamentales: la directiva 2000/43, relativa a la aplicación del principio de igualdad de trato de las personas independientemente de su origen racial o étnico, y la directiva 2000/78, relativa al establecimiento de un marco general para la igualdad de trato en el empleo y la ocupación. Las mencionadas directivas constituyen el mínimo legal que todos los Estados miembros de la Unión deben integrar en sus órdenes jurídicos respectivos.

La lucha contra la discriminación tendrá una dimensión más bien jurídico-represiva, mientras que la promoción de la igualdad conservará un carácter de tipo político-preventivo.

El derecho europeo de la no-discriminación es complejo, ya que contiene no solo el orden jurídico de la Unión Europea (27 países) sino también el derecho convencional del Consejo de Europa (47 países). En este último caso, la prohibición de la discriminación se encuentra contemplada en el artículo 14 del Convenio Europeo de Derechos Humanos (CEDH), según el cual «toda persona goza de los derechos reconocidos en el presente Convenio sin distinción por razones de sexo, raza, lengua, convicciones políticas o religiosas u origen». El protocolo 12 al CEDH amplía el alcance de la prohibición al establecer que «el goce de todos los derechos reconocidos por la ley ha de ser asegurado sin discriminación alguna, en particular por razones de sexo, raza, color, lengua, religión, opiniones políticas o de otro carácter, origen nacional o social, pertenencia a una minoría nacional, fortuna, nacimiento o cualquier otra situación. Nadie podrá ser objeto de discriminación por parte de cualquier autoridad pública, basada en particular en los motivos mencionados en el apartado anterior». El protocolo 12, que aún no ha sido ratificado por el conjunto de los países signatarios del CEDH, confiere un carácter independiente a la prohibición de la discriminación, contrariamente a lo que sucede 
actualmente, que solo puede invocarse el artículo 14 en relación con un derecho consagrado por el CEDH.

La Carta de Derechos Fundamentales de la Unión Europea, que entró en vigor en 2009 con el Tratado de Lisboa, incorpora un nuevo artículo 21 de prohibición de cualquier forma de discriminación ${ }^{2}$. Asimismo, el Tratado de Lisboa contiene una disposición que invita a la Unión Europea a firmar el CEDH como si se tratase de un Estado más, de tal modo que podría el Tribunal Europeo de Derechos humanos (TEDH) juzgar la acción de la Unión en materia de derechos fundamentales. Esto aún no se ha implementado y, por ahora, el único modo de llegar al TEDH es a través del agotamiento de la vías jurisdiccionales internas de los Estados miembros del Consejo de Europa.

Del mismo modo, cabe señalar que los convenios internacionales relativos a la igualdad y la no-discriminación firmados y ratificados por los países europeos forman parte de las fuentes del derecho de la no-discriminación, pero su carácter es menos represivo que el derecho europeo, el cual es de aplicación coercitiva para los Estados miembros.

La protección contra la discriminación se encuentra tanto en la normativa de la UE como en el CEDH y en los convenios internacionales. Aunque estos últimos son suplementarios, es necesario conocer sus particularidades para una eficaz utilización de todas las fuentes jurídicas disponibles.

Teniendo en cuenta lo dicho anteriormente, nos concentraremos principalmente en el derecho de la Unión Europea y en el derecho del CEDH, ya que son los que determinan la dinámica de protección contra la discriminación en el Viejo Mundo. Dichos ordenamientos son complementarios y por ello garantizan una mayor y mejor tutela. El derecho del CEDH se arraiga en una concepción más clásica de la prohibición de la discriminación basada en la filosofía de los derechos humanos, mientras que el derecho de la UE se funda en una visión más pragmática que tiene como finalidad la cohesión social y la integración económica ${ }^{3}$. La Carta de los Derechos Fundamentales de la UE podría considerarse como el encuentro entre estas dos perspectivas y su retroalimentación, pero su reciente adopción no nos permite aún conocer el alcance efectivo de dicho instrumento.

2 «1. Se prohíbe toda discriminación, y en particular la ejercida por razón de sexo, raza, color, orígenes étnicos o sociales, características genéticas, lengua, religión o convicciones, opiniones políticas o de cualquier otro tipo, pertenencia a una minoría nacional, patrimonio, nacimiento, discapacidad, edad u orientación sexual. 2 . Se prohíbe toda discriminación por razón de nacionalidad en el ámbito de aplicación del Tratado constitutivo de la Comunidad Europea y del Tratado de la Unión Europea y sin perjuicio de las disposiciones particulares de dichos Tratados".

3 BORRILlo, Daniel. "Apport philosophique et contribution pratique du droit européen en matière de lutte contre les discriminations». En Eric Fassin y Jean-Louis Halpérin (dirs.). Discriminations: Pratiques, savoirs, politiques. Paris: La Documentation Française, coll. «Etudes et Recherches», 2009, pp. 33-48. 
El relativo éxito de la lucha contra la discriminación en Europa se explica por la articulación de ambas dinámicas: la económica (mercado) y la jurídica (derechos humanos). Además, cabe señalar que la prohibición de la discriminación no es una utopía proclamada por disposiciones desprovistas de consecuencias punitivas. Las autoridades judiciales nacionales están obligadas a aplicar la normativa antidiscriminatoria, independientemente de que las partes del proceso la invoquen. Los Estados y los particulares (personas físicas o jurídicas) pueden así ser sancionados por los jueces nacionales, que están obligados a aplicar el CEDH y las normas de la UE, y si no lo hacen, una autoridad superior (el TEDH o el TJUE) puede sancionar al Estado refractario ${ }^{4}$.

\section{LA ESTRUCTURA DEL DERECHO DE LA NO- DISCRIMINACIÓN}

No intento en este artículo realizar un estudio exhaustivo del derecho de la no-discriminación: varios trabajos, manuales y guías se han abocado a dicha tarea de manera minuciosa ${ }^{5}$. La originalidad de mi reflexión reside en la sistematización de una disciplina particularmente compleja debido a su enorme casuística. No comentaré aquí la numerosa jurisprudencia que implementa la normativa europea tanto en la gran Europa (47 países del Consejo de Europa) como en la pequeña Europa (los 27 países de la UE). Se trata de dar al lector una grilla de lectura que permita sistematizar de manera teórica el material relativo a la lucha contra la discriminación. Para ello, es necesario comenzar con una primera definición de la discriminación y luego decorticar sus elementos sustanciales, los cuales nos permitirán determinar el alcance y la posible resolución de los conflictos relativos a los tratamientos diferenciados no justificados.

Discriminar significa tratar de manera menos favorable a una persona (física o moralmente) de otra en una situación análoga. El tratamiento o tracto aparece así como el primer elemento que se debe tomar en cuenta para establecer la existencia de una situación discriminatoria.

Una discriminación es, además, una distinción que opera en función de un elemento (real o imaginario) de la persona discriminada, tal como su raza, su religión, su nacionalidad, su género, etcétera. El segundo elemento que debemos analizar es, entonces, el criterio de distinción prohibido: criterium.

4 BORRILlo, Daniel. «Les instruments juridiques français et européens dans la mise en place du principe d'égalité et de non discrimination». Revue Française des Affaires Sociales, 56, 1 (janviermars 2002), pp. 113-129.

5 Ver Manual de legislación europea contra la discriminación. Bélgica: Agencia de los Derechos Fundamentales de la Unión Europea y Consejo de Europa, 2010.

ELEMENTOS PARA

UNA TEORÍA

GENERAL DE

LA IGUALDAD

Y LA NO-

DISCRIMINACIÓN

A PARTIR DE LA

EXPERIENCIA

DEL DERECHO

EUROPEO

ELEMENTS FOR A

GENERAL THEORY

OF EQUALITY

AND NON

DISCRIMINATION

REGARDING

EUROPEAN

EXPERIENCE 
Pero la discriminación no se produce en cualquier ámbito de la vida de los individuos sino en un espacio determinado, como el trabajo, la vivienda o la sanidad. Al perímetro dentro del cual puede producirse la discriminación lo denominaremos spatium.

Veamos ahora más detenidamente los diferentes componentes mencionados:

\section{Tracto}

Discriminar consiste en tratar de manera diferente a personas en situaciones similares sin una razón legítima. El tratamiento discriminatorio puede consistir en un acto voluntario (discriminación directa) o ser el resultado de una disposición, un criterio o una práctica aparentemente neutros que afecta de un modo sustancialmente más perjudicial a un grupo determinado en comparación con otro grupo en situación similar (discriminación indirecta).

Para que el tratamiento diferencial en situaciones análogas sea considerado discriminatorio, no deben existir excusas objetivas y razonables que lo justifiquen; además, el fin perseguido debe mantener una relación de proporcionalidad razonable con los medios empleados. En tales casos hay diferenciación, pero no discriminación.

La diferencia entre la discriminación directa e indirecta es que en esta última no existe ninguna responsabilidad individual sino un efecto o resultado discriminatorio que se puede constatar. Por ello, en el plano penal solo pueden sancionarse discriminaciones directas.

Existirá una discriminación directa cuando por algunos de los motivos prohibidos (raza, etnia, sexo, religión...) una persona sea tratada de manera menos favorable de lo que sea, haya sido o vaya a ser tratada otra en situación comparable. La discriminación indirecta se constata cuando, por ejemplo, el cálculo de las pensiones de jubilación se realiza en función del tiempo efectivamente trabajado (disposición neutra), pero en los hechos son las mujeres las que perciben una jubilación menor, ya que son ellas las que trabajan en la gran mayoría de los casos a tiempo parcial (TJUE. Hilde Shönheit c. Stadt Frandfurt am Main y S. Becker c. Land Hessen, 23 octubre de 2003).

El tratamiento discriminatorio también puede tomar la forma del acoso sexual o moral. El artículo 1.3 de la directiva 2000/78 afirma que «el acoso constituirá discriminación a efectos de lo dispuesto en el apartado 1 cuando se produzca un comportamiento no deseado relacionado con alguno de los motivos indicados en el artículo 1 que tenga como objetivo o consecuencia atentar contra la dignidad de la persona y crear un entorno intimidatorio, hostil, degradante, humillante u ofensivo». 
No solo un acto material sino también un discurso discriminatorio, como las órdenes, instrucciones o incitación a discriminar, son asimiladas a una discriminación, como cuando, por ejemplo, una empresa informa a su servicio de recursos humanos que no contrate extranjeros o cuando un parlamentario afirma que ciertas comunidades extranjeras impiden a los ciudadanos gestionar su propio Estado ${ }^{6}$.

La discriminación por asociación es considerada, asimismo, un tratamiento discriminatorio; es el caso de la situación en la que una persona es tratada de manera menos favorable no por razón de una característica individual, sino por la relación con una persona que presenta las características protegidas (por ejemplo, una empleada que es discriminada por el hecho de tener un hijo discapacitado).

Ciertas excepciones y medidas especiales, aunque constituyen un tratamiento diferenciado, no son consideradas discriminatorias. Además de la justificación general que hemos mencionado, relativa a la ausencia de una causa objetiva y razonable, existen justificaciones específicas. Así, «los requisitos profesionales esenciales» aparecen en todas las normativas del derecho europeo como una causa de justificación. El artículo 14(2) de la Directiva de Igualdad de Trato entre Hombres y Mujeres de 2006 establece que: «los Estados miembros podrán disponer, por lo que respecta al acceso al empleo, incluida la formación pertinente, que una diferencia de trato basada en una característica relacionada con el sexo no constituirá discriminación cuando, debido a la naturaleza de las actividades profesionales concretas o al contexto en que se lleven a cabo, dicha característica constituya un requisito profesional esencial y determinante, siempre y cuando su objetivo sea legítimo y el requisito proporcionado». Del mismo modo se establece dicha justificación respecto de la raza y los otros motivos prohibidos.

La religión también puede ser una excepción, ya que el derecho europeo permite a determinadas organizaciones religiosas imponer ciertas condiciones a sus empleados, pero dicha excepción juega únicamente para las personas que ocupan un lugar dentro de los cuadros litúrgicos (como los sacerdotes, que solo pueden ser hombres) y no respecto de los empleados o los profesores de instituciones religiosas.

La edad constituye también una excepción, ya que los empleadores pueden exigir una experiencia de trabajo y los Estados establecer, por ejemplo, edades máximas para las personas activas que serán obligadas a jubilarse, sin que ello sea considerado discriminatorio. En ese sentido, la discriminación por razón de edad constituye el único motivo en el que puede justificarse objetivamente una discriminación directa. 


\section{Criterium}

El criterio prohibido es un elemento fundamental a efectos de determinar la existencia de un trato discriminatorio. Para ello, es necesario comparar la situación de la supuesta víctima y la de otra persona que no posee las características o se encuentra en la categoría prohibida. Para que se constituya la discriminación, es necesario determinar un vínculo de causalidad entre el tratamiento menos favorable y el criterio prohibido. En ausencia de un nexo de causalidad, no habrá discriminación.

El CEDH, las directivas comunitarias, la Carta de los Derechos Fundamentales de la UE y las legislaciones de los países miembros establecen diferentes categorías prohibidas de discriminación. De la lectura de los instrumentos jurídicos europeos se desprenden dieciséis categorías prohibidas: sexo, raza, color, origen étnico, origen social, características genéticas, lengua, religión, convicciones, opiniones políticas, nacionalidad, patrimonio, nacimiento, discapacidad, edad y orientación sexual. Dicha lista no es exhaustiva, ya que la normativa europea introduce al final de la enumeración la expresión «o cualquier otro motivo», dejando así a los jueces la posibilidad de proteger situaciones no previstas explícitamente.

Históricamente el género aparece como la primera categoría protegida por el derecho comunitario, y ello porque Francia temía que su legislación nacional, al proteger particularmente al género femenino — cosa que no hacían los otros ordenamientos jurídicos europeos del mismo modo-, ubicase a Francia en situación de competencia desleal respecto de los otros países de la Comunidad Europea. Las discriminaciones basadas en el sexo son las que más han desencadenado acciones judiciales relativas sobre todo a la desigualdad de remuneración entre hombres y mujeres. En Francia, según un estudio del INSEE de 2012, una mujer gana en promedio entre 18 y 20\% menos que un hombre en situación laboral análoga ${ }^{7}$. Algunas legislaciones nacionales establecen un criterio específico de discriminación relacionado con el embarazo. La legislación europea incluye dicha situación en la categoría género.

Contextos extrapatrimoniales también han sido considerados como discriminatorios para las mujeres, quienes en Turquía, por ejemplo, están obligadas a adoptar el apellido del marido cuando se casan mientras que los hombres no deben hacerlo, situación sancionada por el juez europeo (TEDH, Unal Tekeli c. Turquía, 16/11/2004).

Los hombres también son protegidos por dicha categoría, así como las personas transidentitarias. En el derecho francés, dichas personas se encuentran dentro de un criterio específico: la identidad sexual. Dicha categoría protege a las personas que no se sienten conformes

7 http://www.insee.fr/fr/themes/document.asp?reg_id=0\&ref_id=FPORSOC11f_VE31Sal 
con el sexo asignado al nacimiento y que se han sometido a procesos de modificación física y hormonal, pero también a aquellas que solo adoptan comportamientos vestimentarios del sexo opuesto.

La raza, el origen étnico, el color de la piel o la pertenencia a una minoría nacional es el otro gran criterio prohibido de discriminación del derecho europeo y el que, después del género, ha producido la mayor jurisprudencia. Así como respecto del género, una disposición específica sanciona dicha forma de discriminación (directiva 2000/43) no solo en el ámbito del empleo, de la seguridad social y del acceso a bienes y servicios (como en el género), sino también respecto del sistema general de bienestar social, incluyendo el acceso a la vivienda, a la educación y al ocio. Aunque no existe una definición jurídica de dicha categoría, el TEDH ha señalado que «la etnia y la raza son conceptos relacionados que se solapan. Mientras que el concepto de raza parte de la idea de la clasificación biológica de los seres humanos en subespecies con arreglo a rasgos morfológicos como el color de la piel o las características faciales, la etnia tiene su origen en la idea de los grupos sociales marcados por la nacionalidad, la afiliación tribal, la fe religiosa, la lengua compartida o los orígenes y antecedentes culturales comunes» (TEDH, Timishev c. Rusia, 13/12/2005). La legislación francesa se refiere a la «raza o pertenencia étnica real o supuesta», permitiendo así sancionar los comportamientos respecto de aquellos que suponen que una persona, por algunas de sus características personales, pertenece a una raza o una etnia determinada, aunque eso no sea verdad. Si bien esto funciona de la misma manera en el derecho europeo, la indicación expresa de «real o supuesta» permite descartar cualquier malentendido.

La religión y la nacionalidad constituyen criterios prohibidos de discriminación específicos, aunque muchas veces se encuentran asociados a la raza. El derecho europeo protege igualmente las creencias que no tienen un fundamento religioso, como aquellas relativas a los ateos, los agnósticos y las personas indiferentes. Se tutela de la misma manera a quien profesa como a quien no profesa una religión, ya que se trata de cuestiones personales y subjetivas.

El ordenamiento jurídico francés es menos protector de ciertas religiones consideradas como sectas, tales como la cienciología o los testigos de Jehová, a quienes no solo no se les reconoce el estatuto de religión sino que se les prohíbe una cierta cantidad de actividades ${ }^{8}$. Del mismo modo, los signos religiosos ostentatorios están prohibidos para los menores en las escuelas públicas.

ELEMENTOS PARA UNA TEORÍA GENERAL DE LA IGUALDAD Y LA NODISCRIMINACIÓN A PARTIR DE LA EXPERIENCIA DEL DERECHO EUROPEO

ELEMENTS FOR A GENERAL THEORY OF EQUALITY AND NON DISCRIMINATION REGARDING EUROPEAN EXPERIENCE 
Otro de los criterios prohibidos es la nacionalidad, la cual es definida por el derecho europeo como «el vínculo legal entre una persona y el Estado». El derecho de los Estados a regular la inmigración es reconocido por el orden jurídico internacional y no constituye per se una discriminación. La libre circulación entre ciudadanos miembros de la UE otorga beneficios a los nacionales de dichos Estados, sin que ello sea considerado discriminatorio respecto de otros Estados no miembros.

La orientación sexual es la atracción física o emocional hacia personas del mismo sexo (homosexual), del sexo opuesto (heterosexual) o indistintamente de ambos sexos (bisexual). Una abundante jurisprudencia del TEDH y del Tribunal de Justicia de la Unión Europea (TJUE) sanciona las discriminaciones hacia las personas gay, lesbianas y bisexuales como una violación a su vida privada y familiar, tanto respecto de la administración como de particulares.

La discapacidad ha sido definida por el TJUE como toda «limitación que se deriva, en particular, de deficiencias físicas, mentales o psicológicas, y que dificulta la participación de la persona en cuestión en la vida profesional», y añade que «ha de ser probable que tal deficiencia se mantenga durante un período prolongado». Las situaciones más frecuentes de discriminación por discapacidad se constatan en el ámbito laboral, pero también pueden encontrarse en otros ámbitos de la vida, como el transporte, el alojamiento, el acceso a actividades recreativas, etcétera. El derecho europeo no protege a la discriminación por razón de enfermedad, como lo hace el derecho francés. En efecto, algunas patologías, sin llegar a constituir un hándicap, pueden ser consideradas como un criterio prohibido de discriminación fundado en el estado de salud, por ejemplo, el rechazo por parte de un dentista de tratar a un paciente seropositivo.

El origen social, el nacimiento, la propiedad, así como las opiniones políticas, no se encuentran protegidas por el derecho de la UE pero sí por la jurisprudencia del TEDH. Las opiniones políticas son tuteladas efectivamente en función del artículo 10 del CEDH relativo a la libertad de expresión más que como una forma de discriminación.

La categoría origen social es quizás la más paradójica y la que mejor revela las contradicciones del sistema. De hecho, desde la adopción de los instrumentos de lucha contra la discriminación, la pobreza no ha cesado de aumentar en Europa y los países más pobres de la UE son también los que distribuyen peor la renta, presentando tasas más altas de pobreza relativa (Grecia y Portugal 21\%, España 19\%). Pero la manera de distribuir la renta, aunque aparece como el elemento determinante de la discriminación fundada en el origen social y el patrimonio, no es considerada como tal por la UE, que deja a los Estados decidir sus políticas fiscales. 


\section{Spatium}

El perímetro de protección contra la discriminación no es el mismo para el derecho convencional europeo que para el derecho de la UE. En el Consejo de Europa el ámbito es más amplio, pues se refiere a todos los derechos fundamentales tutelados por el CEDH (derecho a la vida privada, la libertad, la propiedad, el matrimonio, la vida familiar, el debido proceso...). En la UE, en cambio, el ámbito del empleo aparece hoy día como el más protegido en materia de discriminación. Se entiende por empleo a las relaciones de dependencia, desde el origen de la contratación, el desarrollo de la carrera, las promociones... hasta el fin del contrato. Las pasantías son asimiladas a relaciones de empleo.

La directiva sobre igualdad racial extiende dicho ámbito al acceso a bienes y servicios, al sistema público de seguridad social y demás prestaciones (educación, vivienda...). Después de la raza, es el género la categoría mejor protegida, ya que su ámbito es el empleo, la seguridad social y el acceso a bienes y servicios. Respecto de la orientación sexual, la religión, la discapacidad y la edad, solo se encuentran protegidas contra la discriminación en el empleo.

Vemos, pues, que a la hora de determinar una situación de discriminatoria no todas las personas se encuentran protegidas de la misma manera, y aunque el derecho de la UE obra actualmente por una unificación de los diferentes ámbitos y criterios, por el momento una jerarquía persiste. Por ello, es importante escoger la categoría mejor protegida. Así, por ejemplo, si una persona es discriminada por su religión pero resulta que a su vez dicha religión es característica de una etnia o una raza, es más conveniente incoar una acción por discriminación racial que religiosa, ya que la primera se encuentra protegida de manera más amplia.

Pueden también existir discriminaciones múltiples; es decir, aquellas en que una persona es a su vez discriminada por dos o más criterios prohibidos. En estos casos, generalmente uno de los motivos de discriminación se encuentra agravado por otro motivo, por ejemplo una mujer negra o un gay musulmán. En estos casos es necesaria una metodología específica para entender la situación de discriminación, que no puede resumirse a la suma de dos o más tipos de discriminación, sino al efecto amplificador que tiene la discriminación múltiple.

El límite efectivo de la discriminación múltiple es que el derecho europeo no considera como criterio susceptible de potencializar la discriminación el origen social, cuando en realidad dicha situación es la que más generalmente agrava los otros criterios. Aquí vemos la victoria de la concepción anglosajona de la discriminación (más próxima al mercado) respecto de la concepción continental (más próxima al Estado social). 


\section{LA PRUEBA EN MATERIA DE DISCRIMINACIÓN}

Una de las cuestiones más difíciles en materia de discriminación es la prueba, ya que en la mayoría de los casos el motivo de un tratamiento diferenciado no es revelado por el autor de la discriminación. Consciente de ello, la UE obliga a los Estados miembros a organizar el sistema probatorio de tal manera que las eventuales víctimas no se encuentren imposibilitadas al momento de demostrar una situación discriminatoria.

En materia penal, la víctima debe probar el carácter intencional de la discriminación. Es en el ámbito civil donde el derecho europeo ha producido los principales avances probatorios. Una inversión parcial de la carga de la prueba se produce cuando existen indicios fuertes de discriminación; en tal caso, es a la persona demandada (el empleador, el propietario de un piso o la administración, por ejemplo) a la que le incumbe probar que no ha discriminado y no a la supuesta víctima de sobrellevar dicha carga.

Además de la repartición de la carga de la prueba, otros dos elementos claves han modificado el proceso en materia de discriminación. El primer elemento fundamental es permitir a las asociaciones actuar como parte legitimada en el proceso a nombre propio o en representación de la víctima.

En todo caso, no es necesario demostrar que el autor de la discriminación tiene motivaciones racistas, sexistas o de otro tipo para probar la discriminación: lo que cuenta es la relación de causalidad entre la creación de una situación menos favorable y la categoría prohibida. Tampoco es necesario que la víctima esté determinada o sea determinable: una situación abstracta susceptible de provocar una discriminación puede ser atacada en justicia.

La creación de sanciones contra la posible represalia respecto de los testigos que declaran en un proceso ha sido otro elemento fundamental para hacer eficaz el principio de no-discriminación, ya que muchas personas renunciaban a testimoniar por el temor de ser sancionados por el empleador.

En los casos de discriminación indirecta, los estudios estadísticos y otros trabajos científicos que prueban que un grupo se encuentra en situación de vulnerabilidad constituyen un indicio susceptible de revertir la carga de la prueba. Del mismo modo, las pruebas de discriminación (testing) son elementos admitidos en el proceso. Dicha prueba se basa en un cierto juego de simulación en el que se coloca una persona en situación de cometer una discriminación sin que dicha persona sepa que es observada, por ejemplo, ante ciertas negativas a alquilar determinadas viviendas. Este tipo de prueba es llevado a cabo por asociaciones especializadas, a efectos de evitar posibles abusos. 
El proceso contra la discriminación puede llevar a una conciliación, una transacción o una condena. Los Estados están obligados a adoptar sanciones efectivas, proporcionadas y disuasorias, sanciones que pueden incluir la indemnización a la víctima.

\section{LA PROMOCIÓN DE LA IGUALDAD}

El derecho europeo obliga a los Estados miembros no solo a aplicar la normativa en materia de lucha contra la discriminación sino también a promover la igualdad. Dicha promoción toma una forma proactiva y consiste en pergeñar políticas que van del conocimiento de las discriminaciones a través de la financiación de estudios científicos a la puesta en marcha de campañas en los medios de comunicación y a la creación de guías de buenas conductas para las empresas y la administración.

El derecho europeo obliga a los Estados a adoptar medidas especiales tendientes a corregir situaciones de discriminación estructurales, como por ejemplo la infrarrepresentación de las mujeres en determinados puestos directivos (paridad) o de minorías étnicas en la universidad (acción positiva). Respecto de las personas en situación de hándicap, los «ajustes razonables» forman parte también de la promoción de la igualdad, y si el Estado no los pone en marcha, corre el riesgo de ser sancionado por discriminación indirecta.

La Comisión obliga asimismo a los Estados miembros de la Unión a crear agencias independientes por la igualdad y la lucha contra la discriminación, por lo menos en materia racial y en el ámbito del empleo?. Así, Francia ha creado en 2005 la HALDE (Haute Autorité de Lutte contre les Discrimination et pour l'égalité ${ }^{10}$, que fue absorbida por el Defensor de los Derechos (DD) en 2011 y actúa en todos los casos de discriminación y más allá del empleo. Los particulares pueden acudir directamente al DD o este puede acompañar a las victimas asistiéndola en el proceso. También tiene el poder de proponer una mediación, permitiendo así la resolución del conflicto de manera informal ${ }^{11}$. En 2011, el DD ha recibido 8183 reclamaciones en materia de discriminación, de las cuales el $23,5 \%$ se refería a la discriminación racial y el $23 \%$ a la discapacidad y la salud. El género aparece como la tercera categoría, con 11,6\% de reclamos presentados. El principal ámbito es el empleo ${ }^{12}$.

9 BorRILlo, Daniel. «Study on Equality Bodies set up under Directive 2000/43/EC, 2004/113/EC and 006/54/EC: France». Rapport à la Commission de l'UE, Human European Consultancy, 2010.

10 BorRillo, Daniel. Halde: Actions, limites et enjeux. París: La Documentation Française, coll. «Etudes et Recherches", 2007.

11 BoRRILLO, D., «Acces to justice in case of discrimination: the situation of France». En A. Terlouw, B. Liegl, K. Wladasch y N. Crowley, Access to justice. A sociological study on cases of discrimination in the EU. FRA D/SE/10/05 Final Report Human European Consultancy, November 2011.

$12 \mathrm{http} / / / w w w . d e f e n s e u r d e s d r o i t s . f r / d o c u m e n t a t i o n$

ELEMENTOS PARA

UNA TEORÍA

GENERAL DE

LA IGUALDAD

Y LANO-

DISCRIMINACIÓN

A PARTIR DE LA

EXPERIENCIA

DEL DERECHO

EUROPEO

ELEMENTS FOR A

GENERAL THEORY

OF EQUALITY

AND NON

DISCRIMINATION

REGARDING

EUROPEAN

EXPERIENCE 
Más allá de la represión, quisiera terminar con un ejemplo interesante de prevención que se está realizando en Francia con los editores de manuales escolares para ver cómo se pueden reducir las representaciones discriminatorias en dichos textos. Se trata, por ejemplo, de visibilizar ciertas minorías de manera no estereotipada, como los musulmanes o las personas provenientes de las antiguas colonias africanas. Evitar los clichés sexistas que muestran a la mujer en tareas domésticas o subordinadas es otro de los objetivos de dicha empresa.

Del mismo, modo se intenta sistemáticamente hablar de homosexualidad cuando se trata de educación sexual (no presuponiendo que todos los alumnos sean heterosexuales) o no ocultar la homosexualidad de personajes célebres de la historia nacional, así como recordar que los homosexuales fueron deportados durante el III Reich ${ }^{13}$.

El mecanismo más eficaz para luchar contra los prejuicios continúa siendo la educación, ya que la ignorancia constituye el principal y el más fértil terreno de la discriminación. 